\title{
RESPOSTAS MORFOFISIOLÓGICAS IN VITRO DE PLÂNTULAS DE Anadenanthera colubrina (Vell.) Brenan var. cebil (Griseb) Altschul ${ }^{1}$
}

Cristina Ferreira Nepomuceno², Ana Paula de Souza Rios ${ }^{3}$, Sandra Regina de Oliveira Domingos Queiroz ${ }^{4}$, Claudinéia Regina Pelacani ${ }^{4}$ e José Raniere Ferreira de Santana ${ }^{4}$

\begin{abstract}
RESUMO - Este trabalho teve como objetivo avaliar o estabelecimento in vitro de Anadenanthera colubrina var. cebil, através das respostas morfofisiológicas das plântulas submetidas a várias condições de cultivo. As sementes foram desinfestadas e inoculadas em placas de Petri contendo papel germtest previamente esterilizado e umedecido com água estéril. As placas ficaram no escuro por dois dias até que ocorresse a germinação das sementes e, em seguida, transferidas para tubo de ensaio contendo meio de cultura WPM. Foram avaliados três tipos de fechamentos dos tubos de ensaio: filme de PVC, tampa plástica sem filme de PVC e tampão de algodão. No segundo experimento, o meio de cultura foi suplementado com carvão ativado (0,0; e 82,2 $\mathrm{mM})$ e diferentes concentrações de sacarose $(0,0 ; 29,21 ; 58,43 ;$ e 87,64 mM). Ao final de 30 dias, observaramse efeitos altamente significativos dos tipos de fechamento sobre todas as variáveis analisadas: comprimento da parte aérea (CPA), número de folhas (NF), número de pinas (NP), matéria seca da parte aérea (MSPA), abscisão foliar (AF), comprimento da raiz (CR), matéria seca da raiz (MSR) e número de raízes secundárias (NRS). A AF foi reduzida em 7,3 vezes, quando os tubos de ensaio foram fechados com tampão de algodão em relação ao fechamento com filme de PVC. Os maiores valores de CPA (102,5 mm), NF (3,0), CR (194,7 $\mathrm{mm}$ ) e NRS $(47,88)$ foram obtidos com 29,21 mM de sacarose; a MSPA $(59,1 \mathrm{mg})$, quando utilizou 58,43 mM e MSR (33,37 mg), com 87,64 mM de sacarose. O carvão ativado apresentou efeito significativo apenas em NRS, com maior valor $(45,79)$ na presença desse composto.
\end{abstract}

Palavras-chave: Aeração, sacarose e carvão ativado.

\section{IN VITRO MORPHOPHYSIOLOGICAL ANSWERS OF THE SEEDLINGS OF Anadenanthera colubrina (Vell.) Brenan var. cebil (Griseb) Altschul}

\begin{abstract}
This work aimed to evaluate the in vitro establishment of the species Anadenanthera colubrina var. cebil, throug the morphophysiological answers of the seedlings subjected to several culture conditions. The seeds were desinfested and inoculated in Petri plates containing germtest paper, previously sterilized and imbibed with sterile water. The plates were kept in the dark for two days, until the seeds germinated. Then, they were transferred to the test tube containing WPM medium. Three types of test tube closings were evaluated - PVC film, plastic lid without PVC film and cotton lid. In the second experiment, the culture medium was supplied with activated charcoal $(0,0$ and $82,2 \mathrm{mM})$ and different sucrose concentrations $(0,0 ; 29,21$; 58,43;87,64mM). After 30 days, highly significant effects of the types of closure were observed on all the variables analysed - aereal part length (APL), number of leaves (NL), number of pinnas (NP), dry matter of aereal part (DMAP), leaf abscission (LA), root length (RL), root dry matter (RDM) and number of secondary
\end{abstract}

\footnotetext{
${ }^{1}$ Recebido em 12.03.2007 e aceito para publicação em 24.04.2009.

${ }^{2}$ Programa de Pós-Graduação em Botânica da Universidade Estadual de Feira de Santana - BA. E-mail: <nepomucenocf@yahoo.com.br>

${ }^{3}$ Programa de Pós-Graduação em Biotecnologia da UEFS. E-mail: <riosbioap@ yahoo.com.br>

${ }^{4}$ Departamento de Ciências Biológicas da UEFS .E-mail: <sanqueiroz@ig.com.br>; <pelacani@uefs.br>; <raniere@uefs.br>
} 
roots (NSR). The LA was reduced in 7,3 times when the cotton lid was used instead of the PVC film. The greatest values for APL (102,5 mm), NP (3,0), RL (194,7 mm) and NRS $(47,88)$ were obtained with 29,21 $\mathrm{mM}$ of sucrose. For DMAP (59,1 mg), when it used 58,43mM, and for RDM (33,37 mg), with 87,64mM of sucrose. The activated charcoal showed significant effects only for the variable SRN, presenting the greatest value $(45,79)$ in the presence of this compound.

Keywords: Aeration, sucrose and activated charcoal.

\section{INTRODUÇÃO}

Anadenanthera colubrina (Vell.) Brenan var. cebil (Griseb) Altschul, pertence à família Leguminosae Mimosoideae, possui porte arbóreo e é conhecida como angico. Esta espécie se encontra no grupo de espécies importantes para o enriquecimento do semiárido/caatinga no Estado da Bahia, Brasil, sendo também considerada no manejo para fins silviculturais. Mas, devido à utilização indiscriminada, a sobrevivência da espécie tem sido colocada em risco de extinção.

Diante do grande potencial econômico, social e ambiental do angico faz-se necessário desenvolver metodologias para uma eficiente multiplicação, conservação e manutenção dessa espécie. Embora, como acontece com a maioria das plantas nativas, a propagação da espécie ocorra normalmente através de sementes, essa via de propagação apresenta algumas desvantagens, como a falta de uniformidade, segregação de caracteres e longo tempo para a produção das mudas. Assim, o estudo da propagação vegetativa através da cultura de tecidos pode ser importante ferramenta, proporcionando rápida e eficiente propagação do angico. A micropropagação vem sendo utilizada para a produção em escala comercial, com grandes vantagens devido à obtenção de mudas uniformes e sadias em menor tempo. Para Carvalho et al. (2005), esse método de propagação vegetativa é viável para a multiplicação de indivíduos geneticamente superiores, de forma a obter plantios clonais com alta produtividade e qualidade. Segundo Alves et al. (2004), aliada à micropropagação está a transformação genética em plantas lenhosas, o que tem chamado a atenção no setor florestal. Contudo, a aplicação da técnica de micropropagação ainda é limitada para a maioria das espécies lenhosas com interesse econômico e apresenta problemas como contaminação, oxidação do meio de cultura, baixa taxa de enraizamento (JORDAN, 1988) e multiplicação dos brotos, além do acúmulo de substâncias tóxicas (RASAI et al., 1994; ZOBAYED et al., 2002).

R. Árvore, Viçosa-MG, v.33, n.3, p.481-490, 2009
Entre os compostos tóxicos que se acumulam no interior dos frascos, utilizados em crescimento de cultura, o gás etileno tem sido o foco, pois possui papel importante no crescimento e desenvolvimento in vitro (BIDDINGTON, 1992). Esse regulador de crescimento induz a abscisão foliar e tem-se apresentado como um dos maiores problemas para o cultivo in vitro. $\mathrm{O}$ acúmulo de gases é promovido por alguns fechamentos utilizados nos recipientes, que não permitem trocas gasosas, com o meio externo. Em cultivos com Annona, Zobayed et al. (2002) relataram que as taxas de abscisão são relativamente altas quando estas são cultivadas em recipientes com restrição de trocas gasosas.

A utilização do fechamento dos tubos de ensaio com tampa plástica mais filme de PVC em cultivo in vitro, além de restringir às trocas gasosas favorece a alta umidade dentro dos vasos, podendo ocasionar hiperidricidade e estômatos anormais (KOZAI et al., 1986). Contudo, o crescimento das plântulas em resposta as trocas gasosas na cultura de tecidos depende da espécie, do tipo de recipiente e também do meio de cultura.

O cultivo in vitro é também fortemente dependente da fonte de carbono, uma vez que o material vegetal não encontra condições adequadas de iluminação e concentração de $\mathrm{CO}_{2}$ e, às vezes, não apresentam teores de clorofila suficientes para realizar fotossíntese que sustente o crescimento. Portanto, é necessária a adição de carboidratos no meio de cultura, pois estes fornecem energia metabólica e esqueletos de carbono para a biossíntese de macromoléculas, as quais são necessárias ao crescimento das células (CALDAS et al., 1998). Segundo Santana (2003), entre as fontes de carbono, a sacarose é a mais utilizada em plantas cultivadas in vitro e é considerada a melhor fonte para o crescimento e diferenciação dos tecidos, além de ser absorvida com maior rapidez (FERREIRA et al., 2002; SKREBSKY et al., 2004). 
Outro fator que pode ser benéfico às culturas in vitro é o carvão ativado, por contribuir no processo de rizogênese, por reter parte de todos os elementos que compõem o meio, fixando citocininas residuais trazidas nos tecidos das plantas e absorvendo compostos tóxicos inibidores do enraizamento (GRATTAPAGLIA e MACHADO, 1998), além de ser condição indispensável na indução de processos de morfogênese em muitas espécies (FRIDBORG et al., 1978).

Este trabalho teve como objetivo avaliar as respostas morfofisiológicas das plântulas de A. colubrina submetidas a várias condições de cultivo.

\section{MATERIAL E MÉTODOS}

\subsection{Local de realização do experimento}

Os experimentos foram realizados no Laboratório de Cultura de Tecidos Vegetais, pertencente à Unidade Experimental Horto Florestal da Universidade Estadual de Feira de Santana (UEFS), localizado no Município de Feira de Santana, região do semiárido da Bahia.

\subsection{Material vegetal, desinfestação e condições de cultivo}

Inicialmente, as sementes recém-colhidas de $A$. colubrina foram lavadas em água corrente. Em câmara de fluxo laminar, essas sementes, foram desinfestadas após a imersão em álcool $70 \%$ por $1 \mathrm{~min}$, seguido de solução de hipoclorito de sódio - $\mathrm{NaOCl}$ (água sanitária comercial - $2,5 \%$ de cloro ativo) com duas gotas de detergente neutro por 15 min e lavadas quatro vezes com água destilada estéril. Em seguida, foram semeadas 10 sementes por placa de Petri contendo papel germtest previamente esterilizado e umedecido com água destilada estéril, sendo, então, as placas vedadas com filme de PVC. O conjunto de placas de Petri ficou no escuro por dois dias, em sala de crescimento com temperatura de $25 \pm 2{ }^{\circ} \mathrm{C}$.

Após $48 \mathrm{~h}$ de semeadura, as sementes com protrusão de radícula foram transferidas para tubos de ensaio, contendo $20 \mathrm{~mL}$ de meio sólido WPM (Wood Plant Medium) (LLOYD e McCOWN, 1980), suplementado com sacarose e solidificado com $0,7 \%$ de ágar (Reagen $\left.{ }^{\circledR}\right)$ e acrescido de $1 \mathrm{~mL} . \mathrm{L}^{-1}$ de fungicida (Derosal ${ }^{\circledR} 500$ sc). $\mathrm{O}$ pH do meio de cultura foi ajustado para 5,7 \pm 0,1 (utilizando-se $\mathrm{KOH}$ ou $\mathrm{HCl} 0,1 \mathrm{~N}$ ), antes da autoclavagem à temperatura de $121^{\circ} \mathrm{C}$, por $15 \mathrm{~min}$. Todo o processo de transferência das sementes com protrusão de radícula foi realizado em câmara de fluxo laminar.
As culturas foram mantidas em sala de crescimento com temperatura de $25 \pm 2{ }^{\circ} \mathrm{C}$, sob fotoperíodo de 16 $\mathrm{h}$, com umidade relativa de $50 \%$ e radiação fotossintética ativa de $30 \mu \mathrm{mol} . \mathrm{m}^{-2} . \mathrm{s}^{-1}$.

\subsection{Influência do tipo de fechamento dos tubos de ensaio}

Neste experimento, as sementes com protrusão de radícula foram inoculadas em meio de cultura contendo $87,64 \mathrm{mM}$ de sacarose. Utilizaram-se três tipos de fechamento dos tubos de ensaio: filme de PVC, tampa plástica sem filme de PVC e tampão de algodão.

O delineamento experimental utilizado foi o inteiramente casualizado, composto por três tratamentos (fechamento dos tubos com filme de PVC, tampa plástica sem filme de PVC e tampão de algodão), com 10 repetições. Cada repetição era composta por quatro tubos.

\subsection{Influência do carvão ativado e da sacarose}

As sementes com protrusão de radícula foram transferidas para o tubo de ensaio contendo meio de cultura WPM, suplementado com diferentes concentrações de carvão ativado $(0 ;$ e $82,2 \mathrm{mM})$ e de sacarose $(0,0 ; 29,21 ; 58,43$; e $87,64 \mathrm{mM})$. Com base nos resultados do experimento anterior, utilizou-se o tipo de fechamento dos tubos de ensaio com tampão de algodão.

O delineamento experimental utilizado foi o inteiramente casualizado, com fatorial $2 \times 4$, com 10 repetições e quatro tubos por unidade experimental.

\subsection{Variáveis analisadas}

Aos 30 dias a foram analisadas as seguintes variáveis: comprimento da parte aérea e da raiz $(\mathrm{mm})$, e para a realização da medida utilizaram-se régua graduada em mm; número de folhas, número de pinas, abscisão foliar e número de raízes secundárias, as quais foram realizadas através de contagem. Para a matéria seca da parte aérea e das raízes (mg), inicialmente separou-se a parte aérea da raiz, sendo ambas acondicionadas em sacos de papel e mantidas na estufa com ventilação forçada, com temperatura mantida em $60^{\circ} \mathrm{C}$ até que atingissem peso constante.

\subsection{Análise estatística}

Os dados foram avaliados estatisticamente mediante a análise de variância, testando-se as médias pelo teste de tukey e através de regressão, com relação aos fatores

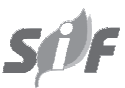

R. Árvore, Viçosa-MG, v.33, n.3, p.481-490, 2009 
qualitativos e quantitativos, respectivamente. Os dados foram analisados usando-se o programa SISVAR, versão 4.3, desenvolvido pela UFLA (FERREIRA, 2003).

\section{RESULTADOS E DISCUSSÃO}

\subsection{Influência do tipo de fechamento dos tubos de ensaio}

As maiores médias do número de folhas e número de pinas foram encontradas quando os tubos de ensaio foram vedados com tampa plástica sem filme de PVC, equivalendo a 2,25 folhas/plântula (Figura 1A) e a 2,8 vezes mais pinas/plântula do que aquelas mantidas em tubos de ensaio fechados com filme de PVC (Figura 1B). Esses resultados estão de acordo com Zobayed et al. (2000), que verificaram, em culturas de segmentos nodais de Eucalyptus camaldulensis, que o número de folhas foi superior (1,4 vez) ao das culturas que estavam em recipientes com restrição de trocas gasosas.

O fechamento dos tubos com tampão de algodão mostrou-se bastante eficiente na redução da abscisão foliar, e quando comparados com o selamento com filme de PVC o decréscimo foi de 7,3 vezes (Figura 1C). Resultados semelhantes foram encontrados por Zobayed et al. (2002) em culturas de Annona squamosa e A. muricata, quando verificaram decréscimo na abscisão foliar através do aumento eficiente da ventilação, demonstrando que a ventilação forçada foi completamente preventiva para a abscisão foliar, em comparação com os vasos herméticos. Em culturas de A. glabra, Santana (2003), usando tampão de algodão, reduziu a abscisão foliar em 12 vezes, em comparação com o selamento com filme de PVC, sem o uso de químicos ou ventilação forçada.

A queda das folhas é um forte indicativo da presença de etileno, que segundo Grattapaglia e Machado (1998) o acúmulo desse regulador de crescimento pode interferir na morfogênese das culturas, acelerando a senescência destas. Em cultivos de Annona realizados por Zobayed et al. (2002), a alta taxa de abscisão foliar nos tubos selados, sem ventilação ou com pouca ventilação, pode ser atribuída ao acúmulo de etileno. Quando esses tubos eram ventilados, houve a redução em $100 \%$ da abscisão foliar nessas culturas. A vedação total dos frascos, além de causar o acúmulo de gases liberados pela cultura, leva à saturação de vapor de água que diminui o fluxo transpiratório nas culturas, podendo causar deficiências minerais de elementos como o cálcio, ocasionando necrose dos ápices (GRATTAPAGLIA e MACHADO, 1998).

Plântulas cultivadas em tubos de ensaio fechados com algodão apresentaram incremento de $56 \%$ no comprimento da parte aérea em relação àquelas cultivadas em tubos de ensaio fechados com filme de PVC (Figura 1D). As folhas apresentaram-se maiores e mais expandidas (dados não mostrados) quando vedados com tampão de algodão. Essa observação corrobora os resultados obtidos das outras culturas in vitro como Solanum tuberosum (KUBOTA e KOZAI, 1992), Rehmannia glutinosa (CUI et al., 2000) e Malus 'Jork 9' (LI et al., 2001). Entretanto, as respostas de crescimento das taxas de ventilação são diferentes de acordo com as espécies, assim como o meio de cultura, a densidade de fluxo fotossintético, a umidade relativa e a concentração de sacarose do meio podem também afetar o crescimento das plantas (KOZAI, 1991).

Cultivos em recipientes com fechamento que possibilite trocas gasosas reduzem o acúmulo de gases e aumenta o fluxo transpiratório, o que aumenta a probabilidade de as plantas sobreviverem durante a fase de aclimatização, uma vez que nessas condições elas apresentam melhor controle transpiratório.

Observaram-se incrementos significativos na matéria seca da parte aérea (20\%) e das raízes (97\%), quando os tubos de ensaio foram fechados com tampão de algodão e tampa plástica sem o filme de PVC, respectivamente (Figura 1EF). Esses resultados estão de acordo com Zobayed et al. (2000) em cultivos de Eucalyptus camaldulensis, que encontraram maior matéria seca da parte aérea e das raízes quando os tubos foram aerados (com ventilação forçada), o que é um caráter desejável, levando a uma melhor qualidade no transplantio. O aumento nas trocas gasosas provavelmente afetou a concentração de $\mathrm{CO}_{2}$ e etileno e a umidade relativa no interior dos tubos. A promoção do crescimento das plântulas de A. colubrina possivelmente pode estar associada a alguns desses fatores, devido à utilização do tampão de algodão, uma vez que este possibilita trocas gasosas entre o meio externo e o interior dos tubos de ensaio. 


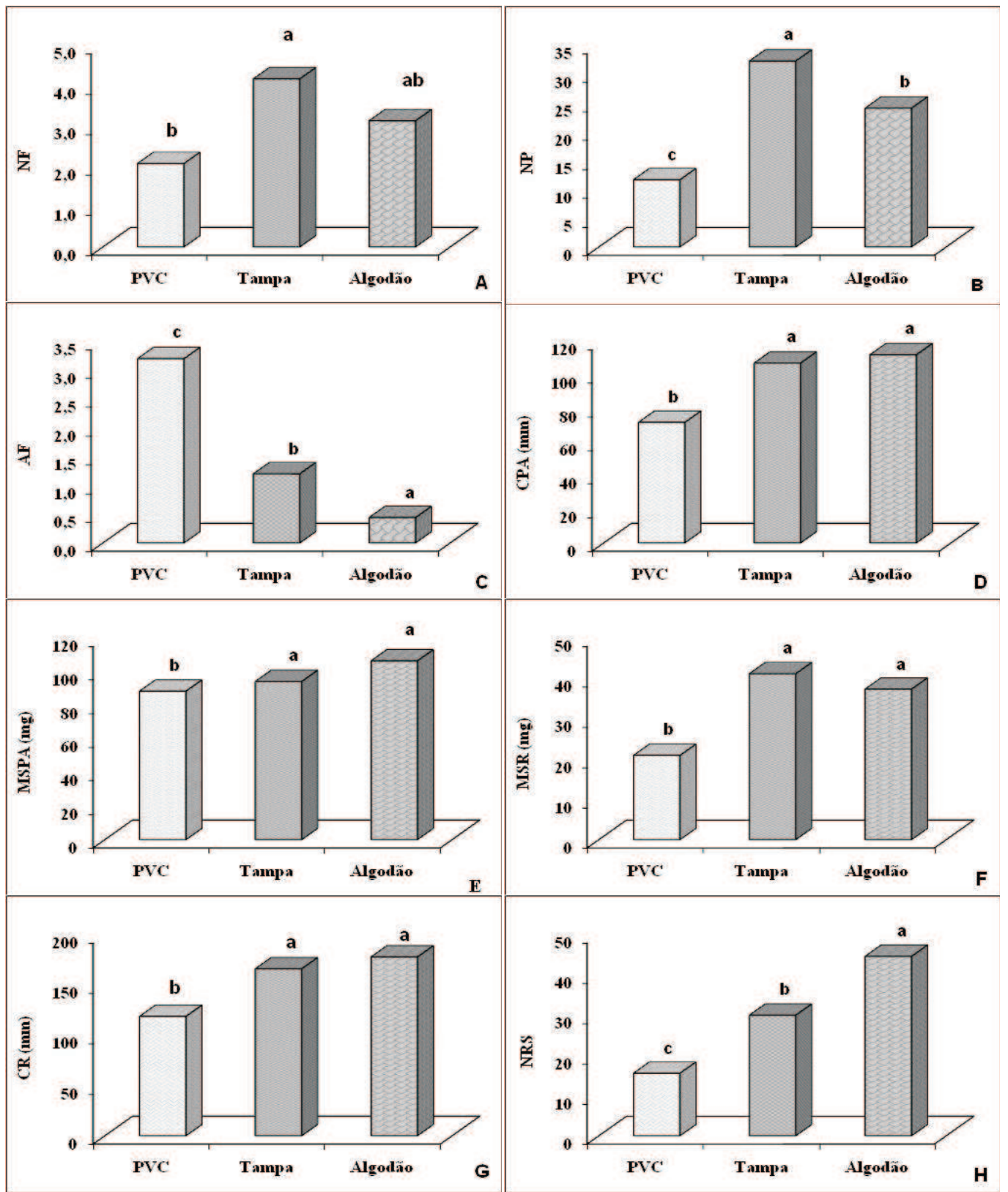

Figura 1 - Médias do número de folhas (NF) (A), número de pinas (NP) (B), abscisão foliar (AF) (C), comprimento de parte aérea (CPA) (D), matéria seca de parte aérea (MSPA) (E), matéria seca de raiz (MSR) (F), comprimento de raiz $(\mathrm{CR})(\mathrm{G})$ e número de raízes secundárias (NRS) (H) de plântulas de $A$. colubrina submetidas à diferentes tipos de fechamento dos tubos de ensaio em meio WPM. Médias seguidas pela mesma letra para cada tratamento (PVC, tampa plástica e tampão de algodão) não diferem entre si ao nível de $1 \%$ de probabilidade pelo teste de Tukey. Feira de Santana, 2006.

Figure 1 - Mean of the number of leaves $(N L)(A)$, number of pinnas $(N P)(B)$, leaf abscission $(L A)(C)$, aereal part lenght $(A P L)(D)$, dry matter of the aerial part $(D M A P)(E)$, dry matter of root $(D M R)(F)$, root length $(R L)(G)$ and number of secondary roots $(N S R)(H)$ of seedlings of A. colubrina var. cebil subject the different type of test tube cover in WPM medium. Means followed for the same for each treatment ( $P V C$ film, plastic lid and cotton lid) do not differ to each other at the 1\% level of probability for the test of Tukey. Feira de Santana, 2006. 
O sistema radicular formado nos tubos de ensaio fechados com tampão algodão apresentou diferenças significativas no comprimento da raiz e no número de raízes secundárias, observando-se incrementos de 50\% e $190 \%$, respectivamente (Figura $1 \mathrm{GH}$ ), corroborando Lucchesini e Mensuali-Sodi (2004), que verificaram maior promoção no enraizamento de brotações de Phillyrea, quando se melhorou a aeração dos tubos, ocorrendo o mesmo com as culturas de oliva (LUCCHESINI e VITAGLIANO, 2002). Logo, o aumento no número de raízes secundárias realça o desenvolvimento da autotrofia, promovendo indiretamente o crescimento e a qualidade da raiz. Entretanto, os dados de A. colubrina diferem dos de Souza et al. (1999), que não observaram diferença significativa entre os tipos de fechamento quando avaliaram o número de raízes e obtiveram comprimento médio das raízes produzidas no cultivo com tampas de metal e plásticas superior às raízes produzidas com o filme de PVC em culturas de Brassica oleracea $\mathrm{L}$. var. capitata L., uma espécie olerícula.

Lucchesini e Mensuali-Sodi (2004) relataram que as brotações de Phillyrea, enraizadas em recipientes aerados, desenvolveram maior biomassa e um sistema radicular extensivo quando mantidas em condições para a transferência ex vitro.

Embora o tampão de algodão permita maior evaporação, redução do volume inicial do meio de cultura em aproximadamente $50 \%$, isso não foi prejudicial ao desenvolvimento da raiz de $A$. colubrina, não causando toxidez às raízes para o seu desenvolvimento, durante o período de 30 dias. O mesmo não foi verificado por Souza et al. (1999), segundo os quais o desenvolvimento das raízes de Brassica oleracea foi prejudicado pela maior concentração de sais devido à evaporação de água do meio de cultura.

Considerando as variáveis avaliadas, as plântulas de A. colubrina crescidas em ambiente aerado (com tampa plástica sem filme de PVC ou tampão de algodão) tiveram crescimento mais vigoroso que aquelas cultivadas em ambiente totalmente fechado (com filme de PVC).

\subsection{Influência do carvão ativado e da sacarose}

Observou-se incremento significativo no número de raízes secundárias na presença de carvão ativado (Tabela1), indicando um aspecto positivo, pois aumento

R. Árvore, Viçosa-MG, v.33, n.3, p.481-490, 2009 no número de raízes pode elevar a capacidade de absorção e favorecer o pegamento das mudas na etapa de aclimatização. De acordo com Assis e Teixeira (1998), a formação de raízes em espécies lenhosas tem sido beneficiada pelo uso dessa substância, uma vez que possui alta capacidade de absorção, bem como propriedade de modificar a composição dos meios de cultura, adsorvendo substâncias adicionadas (citocinina, auxina, vitaminas) ao meio ou liberadas (fenóis e, ou, quinonas) pelos explantes ou presentes no ágar. Essa capacidade de adsorção pode reter tanto substâncias inibitórias quanto promotoras do enraizamento. O carvão ativado também se mostra benéfico ao enraizamento por reduzir a intensidade da luz na região de formação de raízes. Já para matéria seca e para o comprimento da raiz isso não foi observado.

Segundo Nicoloso et al. (2001), a adição de carvão ativado ao meio de cultivo nem sempre tem-se mostrado vantajosa. Em culturas de Pfaffia glomerata, esses autores relataram que, em presença do carvão ativado (82,2 a 246,6 mM), foram observadas respostas negativas tanto da matéria seca da parte aérea quanto do desenvolvimento do sistema radicular. Eles acreditam que a presença do carvão ativado adsorve consideravelmente os elementos químicos presentes no meio, diminuindo a disponibilidade destes. Em cultura de pereira, a concentração de $1 \%$ de carvão ativado adicionado ao meio de cultura não favoreceu o enraizamento, o que foi associado à capacidade que o carvão ativado tem de reter substâncias (ERIG et al., 2004).

Para o efeito da sacarose sobre as respostas morfofisiológicas in vitro de A. colubrina, a análise de regressão mostrou tendência quadrática das concentrações de sacarose para as variáveis número de folhas, número de pinas, comprimento da parte aérea e matéria seca da parte aérea (Figura 2A-D).

Tabela 1 - Valores médios do número de raízes secundárias em plântulas de Anadenanthera colubrina var. cebil, em função de diferentes concentrações de carvão ativado. Feira de Santana, 2006

Table 1 - Mean value of the number of secondary roots in seedlings of Anadenanthera colubrina var. cebil due to the different concentrations of activated charcoal. Feira de Santana, 2006

\begin{tabular}{cc}
\hline Carvão Ativado $(\mathrm{mM})$ & Número de Raízes Secundárias \\
\hline 0,0 & $37,15 \mathrm{~b}$ \\
82,2 & $45,79 \mathrm{a}$ \\
\hline
\end{tabular}




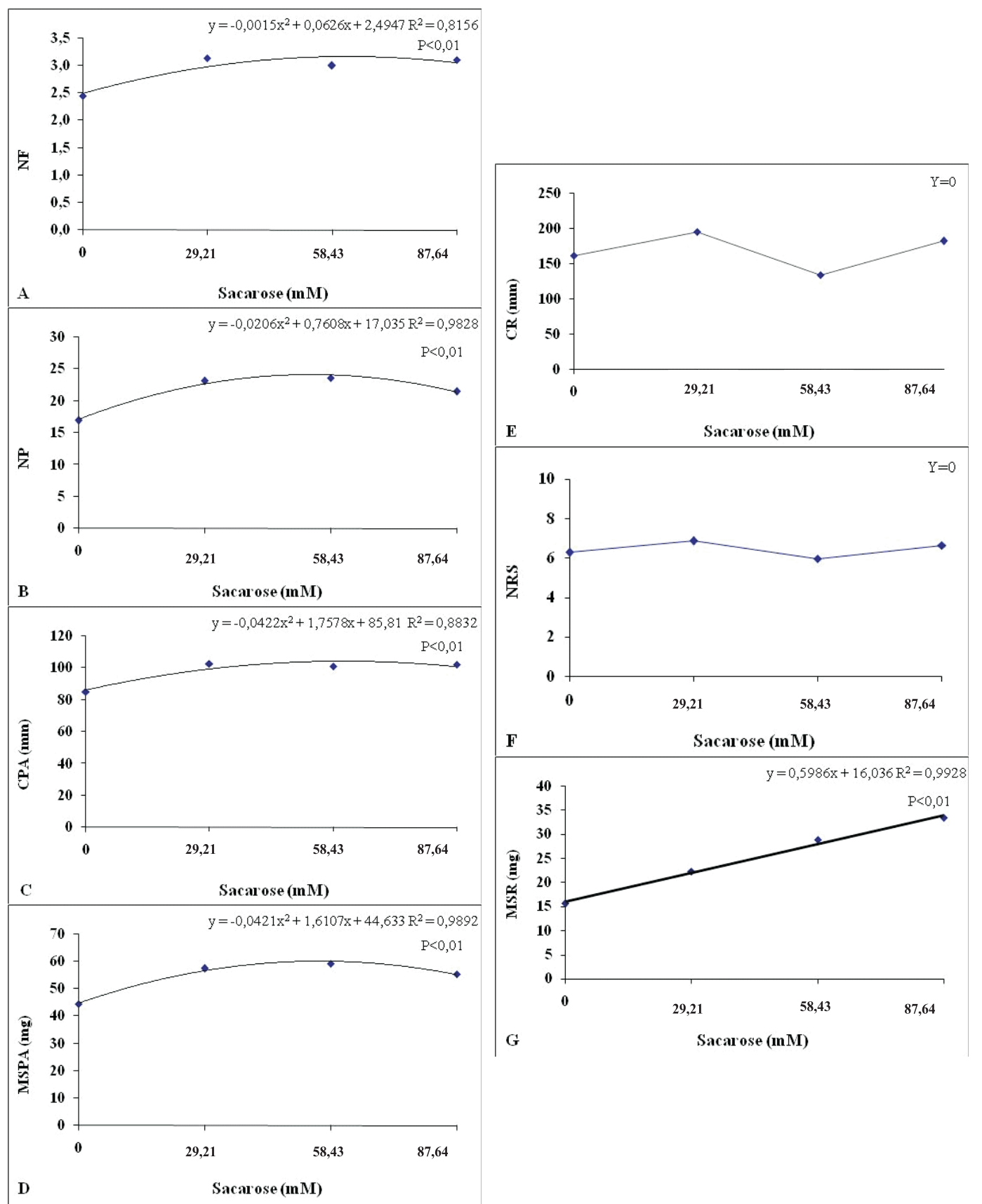

Figura 2 - Valores médios para número de folhas (NF) (A), número de pinas (NP) (B), comprimento de parte aérea (CPA) (C), matéria seca de parte aérea (MSPA) (D), comprimento de raiz (CR) (E), número de raízes secundárias (NRS) (F) e matéria seca de raiz (MSR) (G) de plântulas de A. colubrina submetidas a diferentes concentrações de sacarose em meio WPM. Feira de Santana, 2006.

Figure 2 - Value mean for number of leaves $(N L)(A)$, number of pinnas $(N P)(B)$, aereal part lenght $(A P L)(C)$, dry matter of the aerial part $(D M A P)(D)$, root length $(R L)(E)$, number of secondary roots $(N S R)(F)$ and dry matter of root $(D M R)(G)$ of seedlings of A. colubrina subject the different concentrations of sucrose in WPM medium. Feira de Santana, 2006. 
A maior média do número de folhas por plântula foi obtida $(3,0)$ quando acrescidos ao meio de cultura 29,21 mM de sacarose. Essa condição representou o maior comprimento da parte aérea $(102,5 \mathrm{~mm})$ e da raiz (194,7 mm) e maior número de raízes secundárias $(6,8)$ por plântula (Figura 2ACEF). É provável que essas plântulas tenham sido favorecidas por essa concentração de sacarose, não necessitando de concentrações maiores para o crescimento porque devem ter utilizadas as reservas que se encontram armazenadas nos cotilédones.

Para número de pinas e matéria seca da parte aérea ocorreu o maior valor com 58,43 mM de sacarose (Figura 2BD). Esses resultados são interessantes, uma vez que indica que houve incorporação de carboidrato, aumentando, assim, a energia disponível para as plântulas. Além de indicar melhor qualidade delas, possibilita a utilização desse material vegetal como fonte de explante para a etapa de multiplicação in vitro. Resultados semelhantes foram obtidos em cultivos de Pfaffia glomerata por Skrebsky et al. (2004), quando utilizaram concentrações mais altas de sacarose (196,32 mM). Faria et al. (2004) também verificaram que concentrações mais altas $(175,28 \mathrm{mM})$ de sacarose influenciaram o crescimento e o acúmulo de biomassa das plântulas de Dendrobium cultivadas in vitro. Os carboidratos adicionados no meio de cultura fornecem energia metabólica e esqueletos carbônicos para a biossíntese de aminoácidos e proteínas, polissacarídeos estruturais como celulose, enfim, todos os compostos orgânicos necessários para o crescimento.

Quanto à matéria seca da raiz, observou-se tendência linear crescente com as concentrações de sacarose. Os valores obtidos variaram de $3,89 \mathrm{mg}$ na ausência de sacarose para 5,81 mg com a concentração de 87,64 $\mathrm{mM}$ de sacarose (Figura $2 \mathrm{G}$ ). Esses resultados estão de acordo com os obtidos por Skrebsky et al. (2004), no cultivo de Pfaffia glomerata, em que a resposta para essa variável também se mostrou linear positiva. George (1996) verificou que o aumento da concentração de sacarose, de modo geral, estimula o crescimento e formação de raízes de algumas espécies. Já em outros trabalhos, na fase de enraizamento a redução da concentração de sacarose no meio de cultura vem sendo citada como benéfico na melhoria da qualidade do sistema radicular, bem como na sobrevivência das plântulas transplantadas.

\section{CONCLUSÃO}

O tipo de fechamento dos tubos de ensaio influenciou significativamente o crescimento das plântulas de Anadenanthera colubrina.

O uso de tampa plástica sem filme de PVC ou tampão de algodão proporcionou incrementos significativos no crescimento das plântulas e no controle da abscisão foliar.

A concentração de 29,21 mM de sacarose foi mais eficiente para comprimento da parte aérea, número de folhas, comprimento da raiz e número de raízes secundárias, enquanto no número de pinas e matéria seca da parte aérea foi a 58,43 $\mathrm{mM}$ de sacarose. Já na matéria seca da raiz a melhor concentração foi de $87,64 \mathrm{mM}$ de sacarose.

O carvão ativado foi eficiente apenas na variável número de raízes secundárias.

\section{REFERÊNCIAS}

ASSIS, T. F.; TEIXEIRA, S. L. Enraizamento de plantas lenhosas. In: TORRES, A. C.; CALDAS, L. S.; BUSO, A. J. (Eds.). Cultura de tecidos e transformação genética de plantas. Brasília: Embrapa - SPI / Embrapa - CNPH, 1998. v.1.p.261-296.

ALVES, E. C. S. C.; XAVIER, A.; OTONI, W. C. Organogênese in vitro a partir de explante caulinar na regeneração de clones de Eucalyptus grandis W. Hill ex Maiden X E. urophylla S. T. Blake. Revista Árvore, v.28, n.5, p.643-653, 2004.

BIDDINGTON, N. L. The influence of ethylene in plant tissue culture. Plant Growth

Regulation, v.11, n.2, p.173-187, 1992.

CALDAS, L. S.; HARIDASAN, P.; FERREIRA, M. E. Meios nutritivos. In: TORRES, A. C.; CALDAS, L. S.; BUSO, A. J. (Eds.). Cultura de tecidos e transformação genética de plantas. Brasília: Embrapa - SPI / Embrapa CNPH, 1998. v.1.p.87-132.

CARVAlHO, J. F. R. P.; CARVALHO, C. R.; OTONI, W. C. Regeneração in vitro de urucum (Bixa orellana L.) a partir de diferentes tipos de explantes. Revista Árvore, v.29, n.6, p.887-895, 2005. 
CUI, Y. Y. et al. Number of air exchanges, sucrose concentration, photosynthetic photon flux, and differences in photoperiod and dark period temperatures affect growth of Rehmannia glutinosa plantlets in vitro. Plant Cell, Tissue and Organ Culture, v.62, n.3, p.219-226, 2000.

ERIG, A. C.; WULFFSCHUCH, M.; BRAGA, E. J. B. In vitro rooting of pear tree (Pyrus communis L.) cv. Carrick. Ciência Rural, v.34, n.1, p.275-277, 2004.

FARIA, R. T. et al. In vitro Dendrobium nobile plant growth and rooting in different sucrose concentrations. Horticultura Brasileira, v.22, n.4, p.780-783, 2004.

FERREIRA, D. F. SISVAR - Versão 4.3. DEX/ UFLA. Lavras: 2003.

FERREIRA, M. G. R. et al. Resposta de eixos embrionários de cupuaçu (Theobroma grandiflorum Schum.) à concentração de sais, doses de sacarose e renovação do meio de cultivo. Revista Brasileira de Fruticultura, v.24, n.1, p.246-248, 2002.

FRIDBORG, G. et al. The effects of activated charcoal on tissue cultures: adsorption of metabolites, inhibition of morphogenesis. Physiologia Plantarum, v.43, n.2, p.104-106, 1978.

GEORGE, E. F. Plant propagation by tissue culture. Edington: Exegeties, 1996. $1361 \mathrm{p}$.

GRATTAPAGLIA, D.; MACHADO, M. A. Micropropagação. In: TORRES, A. C.; CALDAS, L. S.; BUSO, J. A. Cultura de tecidos e transformação genética de plantas. Brasília: Embrapa - SPI / Embrapa - CNPH, 1998. v.1.p.183-260.

JORDAN, M. Multiple shoot formation and rhizogenesis from cherimola (Annona cherimola L.) hypocotyls and petiole explants. Gartenbauwissenschaft, v.53, n.5, p.234-237, 1988 .
KOZAI, T.; FUJIWARA, K.; WATANABE, I. Fundamental studies on environments in plant tissue culture vessels. (2) Effect of stoppers and vessels on gas exchange rates between inside and outside of vessels closed with stoppers. Journal of Agricultural Meteorology, v.42, n.1, p.119-127, 1986.

KOZAI, T. Photoautotrophic micropropagation. In Vitro Cell Development Biology Plant. v.27,n.1, p.47-51, 1991.

KUBOTA, C.; KOZAI, T. Growth and net photosynthetic rate of Solanum tuberosum in vitro under forced and natural ventilation. HortScience, v.27, n.12, p.1312-1314, 1992.

LI, R.Y. et al. CO2 enrichment and photosynthetic photon flux affect the growth of in vitro-cultured apple plantlets. Journal Plant Biology, v.44, n.1, p.87-91, 2001.

LLOYD, G.; MCCOWN, B. Use of microculture for production and improvement of Rhododendron ssp. HortScience, v. 15, p.415, 1980. (Abst. 321)

\section{LUCCHESINI, M.; MENSUALI-SODI, A.}

Influence of medium composition and vessel ventilation on in vitro of Phillyrea latifolia L. Scientia Horticulturae, v. 100, n.1/4, p.117-125, 2004.

LUCCHESINI, M.; VITAGLIANO, C. In vitro micro-environments to improve growth of olive plantlets during the rooting phase. In: VITAGLiANO, C.; MARTELLI, G. P. (Eds.) In: OLIVE GROWING, 4., 2002, Romford Road. Proceedings... Romford Road: 2002. p.865-898.

NICOLOSO, F. T. et al. Micropropagação do ginseng brasileiro [Pfaffia glomerata (Spreng.) Pedersen]. Revista Brasileira de Plantas Medicinais, v.3, n.1, p.11-18, 2001.

R. Árvore, Viçosa-MG, v.33, n.3, p.481-490, 2009 
RASAI, S.; KANTHARAJAH, A.S.; DODD, W.A. The effect of growth regulators, sucrose of explants and irradiance on in vitro regeneration of atemoya. Australian Journal of Botany, v.42, n.3, p.333-340, 1994.

SANTANA, J. R. F. Controle da morfogênese in vitro em algumas espécies de Annonaceae. 2003. 237f. Tese (Doutorado em Fisiologia Vegetal) - Universidade Federal de Lavras, Lavras, 2003.

SKREBSKY, E. C.; NICOLOSO, F. T.; FERRÃO, G. E. Sacarose e período de cultivo in vitro de ginseng brasileiro (Pfaffia glomerata Spreng. Pedersen). Ciência Rural, v.34, n.5 p.1471-1477, 2004.
SOUZA, C. M. et al. Influência dos fatores físicos na regeneração de brotos em repolho. Ciência e Agrotecnologia, v.23, n.4, p.830-835, 1999.

ZOBAYED, S. M. A. et al. Mass propagation of Eucalyptus camaldulensis in a scaled-up vessel under in vitro photoautotrophic condition. Annals of Botany, v.85, p.587-592, 2000.

ZOBAYED, S. M. A.; ARMSTRONG, J.; ARMSTRONG, W. Multiple shoot induction and leaf and flower bud abscission of Annona cultures as affected by types of ventilation. Plant Cell, Tissue and Organ Culture, v.69, n.2, p.155-165, 2002.

R. Árvore, Viçosa-MG, v.33, n.3, p.481-490, 2009 